\title{
FIRST ALZHEIMER'S DISEASE PATIENTS TREATED WITH ANTI-DEMENTIA DRUGS: SUSTAINED BENEFITS FOR SOME PATIENTS
}

\author{
MA Watts-Tobin, Consultant in Old Age Psychiatry, \\ Morecambe Bay Primary Health Care Trust; N Horn, SpR in Psychiatry, \\ Royal Liverpool University Hospital; N Radcliffe, Clinical Psychologist, \\ Morecambe Bay Primary Health Care Trust
}

\section{INTRODUCTION}

It seems timely to review our experiences with anticholinesterase treatment for dementia, since the National Institute for Clinical Excellence (NICE) has recently endorsed their use ${ }^{(1)}$. Donepezil was the first of these drugs to be licensed in the UK and we studied our first cohort of 34 patients to see if the benefits described in the research studies were observed in clinical practice. In the research studies ${ }^{(2.3)}$, treatment benefit was measured in terms of improved scores on mental (ie cognitive) tests, regained abilities in everyday activities and reduction of behaviour and mood problems such as wandering, agitation, delusions, and depression: these problems are characteristic of dementing illnesses and are a major cause of distress to carers. The studies have shown unequivocal but modest benefits in cognition at six months, some improvement in functional abilities and a reduction in behaviour problems in the treated groups, compared with the untreated groups. However a major uncertainty in anticholinesterase drug treatment has been variability in response, with some patients showing definite improvements, others showing benefit by maintaining a steady state without deterioration but others continuing to deteriorate. Thus it is not possible to predict response in an individual case, nor the duration of response, and this underlines the need for regular review. Untreated patients, correctly diagnosed, would be expected to deteriorate. On the cognitive tests we used, untreated patients could be expected to lose 3-4 out of 30 points per annum on the Mini Mental State Examination (MMSE) $^{(4)}$ or $12-14$ out of 107 points on the more detailed Cambridge Cognitive Examination for the Elderly $(\mathrm{CAMCOG})^{(5)}$. The NICE guidelines require definitive assessment at three months of treatment and thereafter sixmonthly, and recommend that treatment should only be continued if there is no evidence of deterioration.

The side effect profiles of the three drugs licensed so far (Donepezil, Rivastigmine and Galantamine) are broadly similar and understandable in terms of enhanced cholinergic function ie nausea, diarrhoea, sleeplessness, bradycardia and possible worsening of bronchospasm or gastric ulceration. Side effects are usually mild and transient, lasting up to 48 hours.

\section{METHODS}

Two hundred and thirty patients were assessed for suitability for treatment between May 1997 and August 1998. Patients with probable Alzheimer's type dementia scoring in the mild to moderate (10-26/30) range on the MMSE were started on Donepezil in an open label clinical trial. Thirty-four patients started on treatment, of which five stopped treatment before six months because of side effects, intercurrent illness or noncompliance.

Of the 34 patients, 20 participated in a research study approved by the South Lakeland Research Ethics Committee, with funding from Pfizer/ESAI. This group had repeat cognitive assessments with CAMCOG for an extended follow-up period of 21 months and EEG evoked potential recordings in the Royal Lancaster Infirmary EEG Department. The EEG tests were to see if there was a 'biological marker' of response. The CAMCOG tests were to see if there was a reliable method of predicting response to treatment and also if there was a cognitive test more sensitive than the MMSE to treatment effects.

\section{RESULTS}

In the group of 29 patients who continued for six months of treatment, carers of 15 reported some non-cognitive benefits, which included improved confidence and initiative, reduced anxiety, improved mood and clarity of thinking. These occurred soon after initiating treatment, ie within four weeks, and were greatly valued by carers. Most of these improvements were reported in patients who gained on the cognitive tests, but four without cognitive improvements showed these benefits.

After six months of treatment, nine patients had improved cognitive scores, 13 had neither lost or gained points, and seven had lost at least three points. This represents a cognitive response in three out of four patients.

In the research group of 20 patients, nine of the responders had maintained scores around or above baseline after 15 months of treatment, by which time six patients had discontinued treatment altogether and an intermediate group 
were beginning to deteriorate. At 21 months of treatment seven patients were still scoring around baseline on CAMCOG and their lack of deterioration was confirmed by carer report.

The research study found that EEG evoked potentials showed an improvement in response to treatment but were too difficult to read reliably to draw firm conclusions about their ability to predict response to Donepezil. We found that changes in CAMCOG memory and abstraction subsets predicted longterm response better than changes in MMSE score.

Twenty-five of the 29 patients tolerated the drug

\section{our clinical}

experience supports the use of anti-dementia drugs in selected patients with mild to moderate Alzheimer's disease satisfactorily to the optimum dose (10mg od), although 12 patients within this group had transient side effects such as diarrhoea, muscle cramps or sleep disturbances. Four further patients tolerated $5 \mathrm{mg}$ satisfactorily. Three patients later developed fainting attacks due to cardiac conduction problems and discontinued treatment. No other serious treatment-emergent effects were encountered.

\section{CONCLUSIONS}

- over half the patients we started on Donepezil benefited both cognitively and behaviourally for at least six months of treatment, consistent with previous research studies

- side effects, although frequent, were usually transient

- over one third of patients continued to benefit from treatment for at least 21 months after starting

- the research study did not find a reliable way of predicting response to Donepezil

- our clinical experience supports the use of anti-dementia drugs in selected patients with mild to moderate Alzheimer's disease, with regular monitoring and review, as proposed in the NICE guidelines. To facilitate this, memory clinics are being developed in the bay area focussing on people with early or doubtful dementia.

\section{Acknowledgements}

We would like to thank Mrs Joan Connerton, Mr Brian Bickerstaffe and Dr Sally Pidd for carrying out and reading the EEG studies, Mrs Jacqueline King and Mrs Sandra Kendall for administrative and nursing input and the study participants and their families.

\section{SUGGESTED FURTHER READING}

Jones Roy W Drug Treatment in Dementia. Oxford: Blackwell Science 2000

\section{REFERENCES}

1 National Institute for Clinical Excellence. Guidance on the Use of Donepezil, Rivastigmine and Galanthamine for the Treatment of Alzheimer's Disease. Technology Appraisal Guidance No 19 January 2001

2 Rogers SL, Farlow MR, Doody RS, Mohs R, Friedhoff LT and the Donepezil Study Group. A 24-week, double-blind, placebo-controlled trial of Donepezil in patients with Alzheimer's disease. Neurology 1998;50:136-145

3 Burns A, Rossor M, Guathier S, Petit H, Moller H-J, Rogers SL, Freidhoff LT and the Donepezil Study Group. The Effects of Donepezil in Alzheimer's Disease - Results from a Multinational Trial. Dementia and Geriatric Cognitive Disorders 1999; 10:237-244

4 Folstein MF et al. 'Mini-Mental State': A practical method for grading the cognitive state of patients for the clinician. J Psych Res 1975;12:189-198

5 Roth M et al. CAMDEX - A standardised instrument for the diagnosis of mental disorder in the elderly with special reference to the early detection of dementia. $\mathrm{Br} \mathrm{J}$ Psych 1986;149:698-709

\section{GUIDELINES FOR REFERRAL OF PATIENTS TO LOCAL MEMORY ASSESSMENT CLINICS}

1 dementia suspected

2 carry out Mini Mental State Examination

3 if MMSE $>20 / 30$ refer to memory clinic

4 if MMSE <20 refer for routine community mental health team assessment 